\title{
PROGRAMA BOLSA FAMÍLIA - UMA ANÁLISE SOB A ÓPTICA DAS CONDIÇÕES SOCIOAMBIENTAIS EM QUE VIVEM AS FAMÍLIAS BENEFICIÁRIAS EM UM MUNICÍPIO DA SERRA DO ESPINHAÇO, MG, BRASIL
}

\author{
Natália de Cássia Onuzik¹, Ricardo Tavares², Cláudia Aparecida Marliére de \\ Lima $^{3}$ e Maria Arlene Fausto ${ }^{4}$
}

\begin{abstract}
Resumo: É inegável o impacto do Programa Bolsa Família (PBF) na vida de milhões de famílias brasileiras, porém inúmeras são as estruturas que sustentam a desigualdade social no Brasil, entre elas as condições socioambientais em que vivem as populações. Considerando a importância em articular outras políticas públicas ao PBF, esse estudo propôs investigar, empregando a técnica de Análise de Correspondência (AC), associações entre a situação de pobreza das famílias beneficiárias pelo PBF residentes em um município da Serra do Espinhaço, interior do Estado de Minas Gerais, Brasil, com as condições socioambientais em que vivem. Os resultados revelaram precariedades no que tange a oferta de serviços de saneamento básico no município e a situação estrutural das moradias. Além disso, as insalubridades ambientais diagnosticadas mostraram-se mais graves conforme a severidade da pobreza. Tendo em vista que o fenômeno da pobreza percorre os mecanismos de renda, mas não se esgota neles, é de suma importância que políticas públicas, nesse sentido, sejam elaboradas e articuladas às de transferência de renda, no caso brasileiro, ao PBF, de modo a enfraquecer o cenário das desigualdades no país.
\end{abstract}

Palavras-chave: Programa Bolsa Família. Determinantes socioambientais. Pobreza. Análise de correspondência.

\section{Introdução}

$\begin{array}{llr}\text { Entende-se } & \text { por determinantes } \\ \text { socioambientais } & \text { aqueles } & \text { que, } \\ \text { simultaneamente, } & \text { trazem } & \text { consigo }\end{array}$
características sociais e ambientais, como por exemplo, condições de moradia e acesso aos serviços de saneamento básico (FERREIRA, 2010). Alves (2006) e Véras (2010) demonstraram a sobreposição da cartografia social à ambiental na conceitualização de vulnerabilidade de populações que sofrem com a segregação espacial, desigualdade e exclusão social. De acordo com os autores, grupos populacionais muito pobres $e$ residentes em regiões de risco ambiental são, portanto, considerados em situação de vulnerabilidade socioambiental devido à privação de renda associada à precariedade de infraestrutura, como a cobertura deficiente de esgotamento sanitário e demais serviços urbanos.
É inegável que a pobreza percorra os mecanismos de renda, porém não se esgota neles (MARQUES, 2010). A análise das insalubridades socioambientais permite um melhor diagnóstico da situação de fragilidade das populações, bem como a intervenção direta no combate às externalidades negativas que afetam as comunidades de baixa renda, vítimas da frágil integração intersetorial entre os governos (VÉRAS, 2010; MAZARI et al., 2013). Nesse contexto, encontram-se as famílias beneficiárias pelo Programa Bolsa Família (PBF): programa brasileiro de transferência de renda pautado na lógica das condicionalidades, com foco nas famílias mais pobres, e atuante na quebra do ciclo vicioso da pobreza e na sua redução em longo prazo (BRASIL, 2014).

Seguindo essa linha de raciocínio, ao pensar-se em políticas públicas conjugadas aos mecanismos de assistência social, tornase importante conhecer também a situação

\footnotetext{
${ }^{1}$ E-mail: natalia.nutricaoufop@gmail.com

²E-mail: rtavares77@gmail.com

${ }^{3}$ E-mail: calmarliére@yahoo.com.br

${ }^{4}$ E-mail: mariaarlenefausto@gmail.com

Escola de Nutrição, sala 65, Universidade Federal de Ouro Preto, Campus Morro do Cruzeiro s/n, Bauxita. Ouro Preto, MG, CEP: $35400-000$
} 


\section{REA - Revista de estudos ambientais (Online) v.20, n. 1, p.58-69, jan./jun. 2018}

sanitária em que vivem as populações, dado que, conforme a ideia defendida por Sobral e Freitas (2010), não é possível haver desenvolvimento humano pleno em regiões de vasta desigualdade nas suas mais diversas esferas.

Esse artigo trata da busca de associações entre a situação de pobreza de famílias beneficiárias pelo Programa Bolsa Família (PBF) com as condições de moradia e saneamento básico no espaço geográfico por elas habitado.

\section{Metodologia}

Utilizou-se de um estudo ecológico, censitário, quantitativo, com base em dados secundários originários do Sistema de Cadastro Único para Programas Sociais do Governo Federal Brasileiro (CadÚnico), referentes a todas as famílias beneficiárias pelo PBF no município alvo da pesquisa, cadastradas desde a implementação do programa no ano de 2006, até o mês de dezembro de 2014, num total de 2.910 famílias.

A região estudada, Ouro Preto, está localizada na Serra do Espinhaço, Zona Metalúrgica de Minas Gerais (Quadrilátero Ferrífero), com uma área de $1.245 \mathrm{~km}^{2} \mathrm{e}$ população de 69.598 habitantes, a $96 \mathrm{~km}$ da capital do estado, Belo Horizonte. Sua população nativa é descendente de escravos em decorrência da exploração do ouro pelos portugueses nos tempos do Império. De acordo com o mapa da pobreza e desigualdade dos municípios brasileiros, a incidência da pobreza no local é de $28,54 \%$, com Índice de Gini de 0,43 e taxa de analfabetismo da população maior de 15 anos igual a $5 \%$. A população, em sua maioria, pertence ao sexo feminino $(51,2 \%)$, sendo a mulher o único responsável pelo sustento de $71,8 \%$ dos domicílios. A média de moradores por residência é de aproximadamente 3,4 , e o valor do rendimento médio mensal per capita para os domicílios é de $\mathrm{R} \$ 882,17$ - oitocentos e oitenta e dois reais e dezessete centavos (IBGE, 2010).

Para verificar a associação entre os indicadores socioambientais (abastecimento de água, esgotamento sanitário, destino do lixo, tipo de parede e tipo de piso) e a situação de pobreza das famílias beneficiárias, de acordo com a classificação do PBF (extrema pobreza, pobreza e vulnerabilidade) ${ }^{i}$, foi empregada a análise de correspondência (AC), técnica estatística multivariada indicada no estudo de variáveis categóricas com o objetivo de verificar a atração ou repulsão entre os seus níveis, além de detectar como esses se relacionam com base nas suas distâncias (NASCIMENTO et al., 2013; INFANTOSI; COSTA; ALMEIDA, 2014).

A AC é um método de análise exploratória próprio para tabelas de contingência de duas ou múltiplas entradas, que considera as medidas de correspondência entre as categorias das colunas e das linhas. Esse tipo de análise transfigura uma matriz $Z$ em imagem gráfica, na qual as colunas e linhas são exibidas por categorias ponto (CP) plotadas no gráfico de correspondência, cuja orientação em uma das dimensões (1 e 2) depende das contribuições relativas de cada perfil (linha e coluna), representadas pelas inércias das dimensões 1 e 2. A dimensão de maior contribuição para a interpretação dos dados é dada conforme a sua variabilidade (NASCIMENTO et al., 2013; INFANTOSI, 2014). Largamente utilizada em estudos ecológicos, a AC pode ser considerada uma metodologia estatística refinada, pois facilita a compreensão de dados complexos de modo extremamente didático, além de gerar sucessivas análises de uma dada informação em função do seu caráter multivariado (NASCIMENTO et al., 2013; INFANTOSI; COSTA; ALMEIDA, 2014). Em razão do tipo de análise empregada, fezse necessário, devido às baixas frequências das variáveis isoladas "água encanada" e "banheiro", agrupá-las em uma mesma categoria, conforme descrito no Quadro 1.

Quadro 1 - Caracterização do agrupamento aplicado às variáveis socioambientais "água encanada" e "banheiro" referentes aos domicílios das famílias beneficiárias pelo Programa Bolsa Família no município

\begin{tabular}{|l|c|c|c|}
\hline Variável & Agua encanada & Banheiro & Categoria produzida \\
\hline \multirow{2}{*}{$\begin{array}{l}\text { Água encanada + } \\
\text { Banheiro }\end{array}$} & $\operatorname{Sim}$ & Sim & Sim, Sim \\
\cline { 2 - 4 } & $\operatorname{Sim}$ & Não & Sim, Não \\
\cline { 2 - 4 } & Não & Sim & Não, Sim \\
\cline { 2 - 4 } & Não & Não & Não, Não \\
\hline
\end{tabular}

Fonte: Elaboração própria com base nos dados do Cadastro Único para Programas Sociais do Governo Federal (CadÚnico).ii (BRASIL, 2014) 


\section{REA - Revista de estudos ambientais (Online) v.20, n. 1, p.58-69, jan./jun. 2018}

\section{Resultados e discussão}

Para a interpretação da associação entre os níveis dos perfis linha (água encanada versus banheiro: "Sim, Sim"; "Sim, Não"; "Não, Sim”; “Não, Não") e dos perfis coluna (estratificação da renda: pobreza; extrema pobreza e vulnerável) utilizam-se as Tabelas 1 e 2, respectivamente. A Tabela 1 tem os seus níveis mais satisfatoriamente representados pela dimensão 1 (em negrito), exceto o nível "Sim, Não", o qual possuiu maior contribuição quando interpretado na dimensão 2 (em negrito), ao passo que a Tabela 2 é melhor interpretada na dimensão 1 (em negrito). A Figura 1 retrata o mapa de correspondência entre a (in) existência de água encanada e banheiro nos domicílios e a situação de pobreza das famílias beneficiárias pelo PBF.

Tabela 1 - Contribuições relativas das dimensões 1 e 2 sobre os perfis de linha (água encanada versus banheiro)

\begin{tabular}{l|ll}
\hline Água encanada, Banheiro & $\operatorname{Dim} \mathbf{1}$ & $\mathbf{D i m} \mathbf{2}$ \\
\hline Sim, Sim & $\mathbf{0 , 9 9 2 2}$ & 0,0078 \\
Sim, Não & 0,1041 & $\mathbf{0 , 8 9 5 9}$ \\
Não, Sim & $\mathbf{0 , 9 9 6 4}$ & 0,0036 \\
Não, Não & $\mathbf{0 , 9 7 6 2}$ & 0,0238 \\
\hline
\end{tabular}

Fonte: Elaboração própria com base nos dados do Cadastro Único para Programas Sociais do Governo Federal (CadÚnico) (BRASIL, 2014)

Tabela 2 - Contribuições relativas das dimensões 1 e 2 sobre os perfis de coluna (estratificação da renda)

\begin{tabular}{l|ll}
\hline Estratificação da renda & $\operatorname{Dim} \mathbf{1}$ & Dim 2 \\
\hline Pobreza & $\mathbf{0 , 9 6 3 3}$ & 0,0367 \\
Extrema pobreza & $\mathbf{0 , 9 9 8 4}$ & 0,0016 \\
Vulnerável & $\mathbf{0 , 6 2 1 9}$ & 0,3781 \\
\hline
\end{tabular}

Fonte: Elaboraçãa própria com base nos dados do Cadastro Único para Programas Sociais do Governo Federal (CadÚnico) (BRASIL, 2014)

$\mathrm{Na}$ Figura 1 é possível verificar associação entre famílias beneficiárias do PBF em situação de extrema pobreza com a ausência de água encanada e presença de banheiro em seus domicílios, bem como associação com a ausência de abastecimento por água encanada e banheiro nas residências. Famílias em situação de pobreza e vulnerabilidade estão associadas aos domicílios com abastecimento por água encanada e existência de banheiro, sendo as últimas também associadas com a presença de água encanada, no entanto, ausência de banheiro nas residências.

Para interpretar a associação entre os níveis dos perfis linha (destino do esgoto: direto no rio; fossa; rede pública de esgoto e vala a céu aberto), e dos perfis coluna (estratificação da renda: pobreza; extrema pobreza e vulnerável) são apresentadas e analisadas as Tabelas 3 e 4, respectivamente. A Tabela 3 , referente ao destino do esgoto, traz uma melhor representação de seus níveis pela dimensão 1 (em negrito), exceto para o nível "vala a céu aberto", o qual deve ser interpretado na dimensão 2 (em negrito). A Tabela 4, referente à estratificação da renda, revela uma melhor representação de todos os seus níveis na dimensão 1 (em negrito).

A Figura 2 demonstra a análise de correspondência entre os meios de destino do esgoto e a condição de pobreza das famílias beneficiárias pelo PBF no município. Pode-se observar associação entre famílias beneficiárias em situação de extrema pobreza e domicílios nos quais as formas de destino do esgoto são precárias (vala a céu aberto, fossa e direto no rio). Famílias em situação de pobreza e vulnerabilidade estão associadas com domicílios cuja forma de escoamento sanitário é realizada por meio da rede pública de esgoto. Observa-se também, associação entre famílias em situação de pobreza e domicílios que despejam o esgoto em vala a céu aberto. 


\section{REA - Revista de estudos ambientais (Online) v.20, n. 1, p.58-69, jan./jun. 2018}

Figura 1 - Análise de correspondência entre a disponibilidade de "água encanada mais banheiro" nos domicílios e a condição de pobreza das famílias beneficiários do Programa Bolsa Família no município

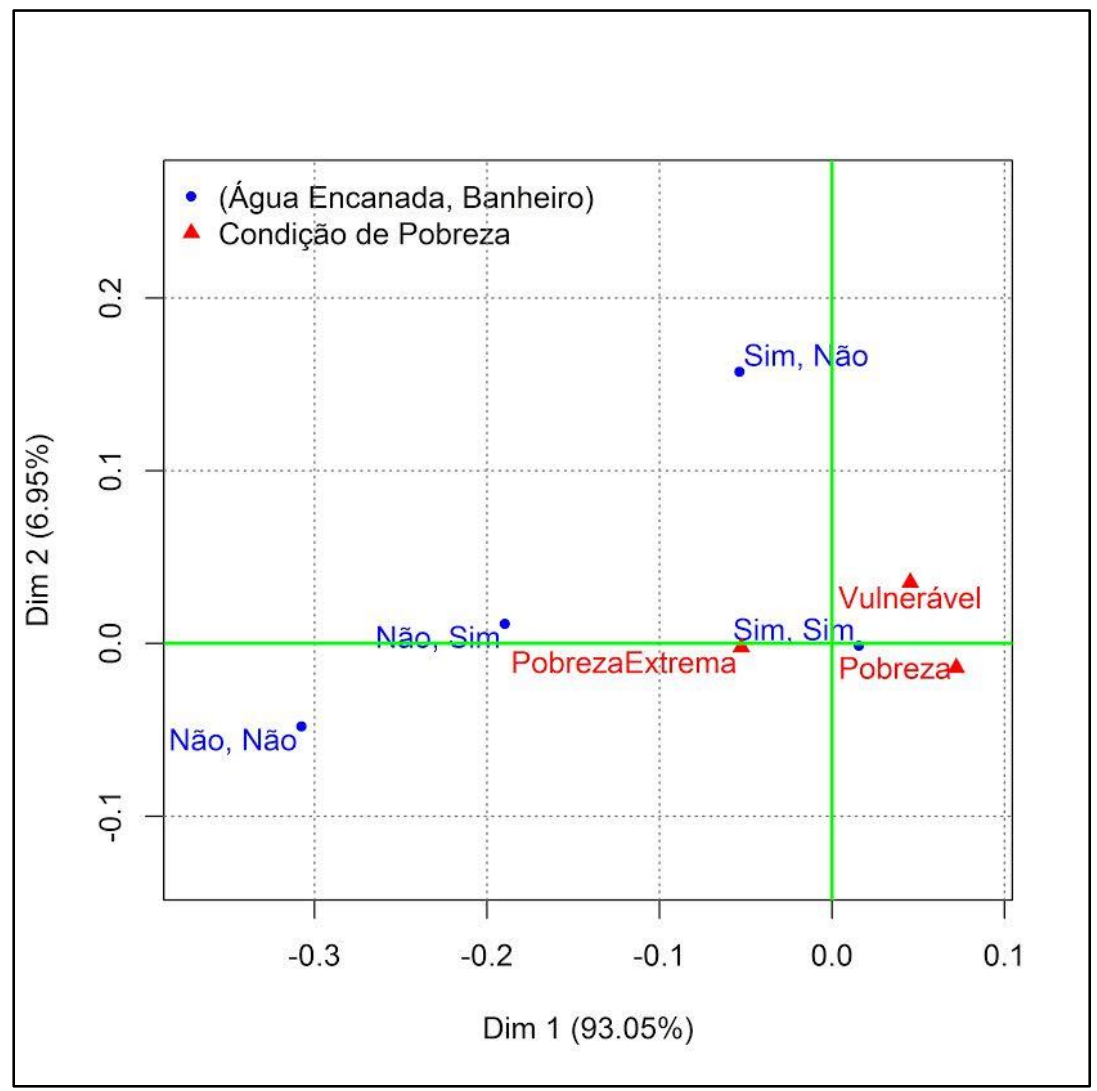

Fonte: Elaboração própria com base nos dados do Cadastro Único para Programas Sociais do Governo Federal (CadÚnico) (BRASIL, 2014)

Tabela 3 - Contribuições relativas das dimensões 1 e 2 sobre os perfis de linha (destino do esgoto)

\begin{tabular}{l|ll}
\hline Destino do esgoto & Dim 1 & Dim 2 \\
\hline Direto Rio & $\mathbf{0 , 9 4 9}$ & 0,051 \\
Fossa & $\mathbf{0 , 9 6 3}$ & 0,037 \\
Rede Esgoto & $\mathbf{0 , 9 9 6}$ & 0,004 \\
Vala Céu Aberto & 0,346 & $\mathbf{0 , 6 5 4}$ \\
\hline
\end{tabular}

Fonte: Elaboração própria com base nos dados do Cadastro Único para Programas Sociais do Governo Federal (CadÚnico) (BRASIL, 2014)

Tabela 4 - Contribuições relativas das dimensões 1 e 2 sobre os perfis de coluna (estratificação da renda)

\begin{tabular}{l|ll}
\hline Estratificação da renda & Dim 1 & Dim 2 \\
\hline Pobreza & $\mathbf{0 , 8 5 7}$ & 0,143 \\
Extrema pobreza & $\mathbf{0 , 9 9 6}$ & 0,003 \\
Vulnerável & $\mathbf{0 , 9 0 8}$ & 0,092 \\
\hline
\end{tabular}

Fonte: Elaboração própria com base nos dados do Cadastro Único para Programas Sociais do Governo Federal (CadÚnico) (BRASIL, 2014) 


\section{REA - Revista de estudos ambientais (Online) v.20, n. 1, p.58-69, jan./jun. 2018}

Figura 2 - Análise de correspondência entre o meio de destino do esgoto e a condição de pobreza dos beneficiários do Programa Bolsa Família no município

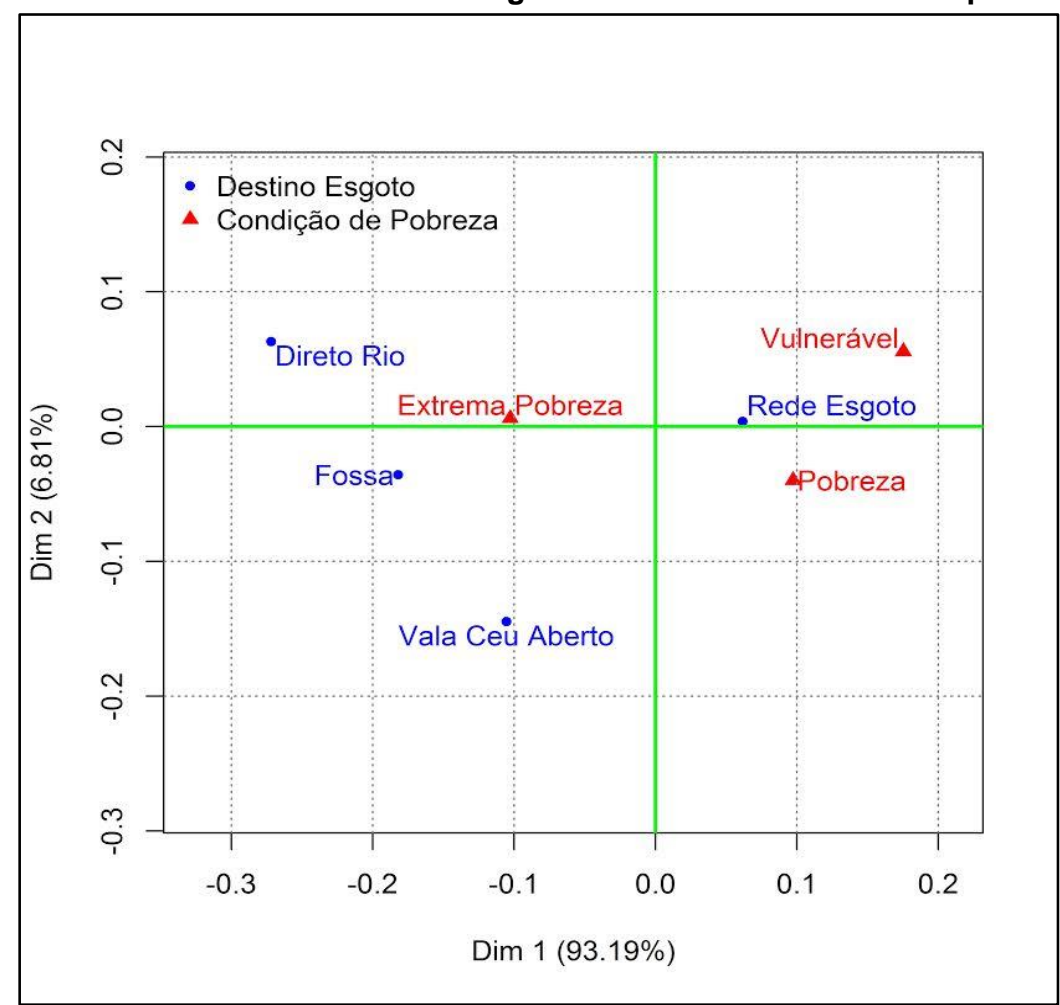

Fonte: Elaboração própria com base nos dados do Cadastro Único para Programas Sociais do Governo Federal (CadÚnico) (BRASIL, 2014)

As Tabelas 5 e 6 trazem os perfis linha (destino do lixo: coletado diretamente; coletado indiretamente; jogado em terreno baldio ou rio; queimado/enterrado), e os perfis coluna (estratificação da renda: pobreza; extrema pobreza e vulnerável). Na Tabela 5, observa-se a representação de todos os seus níveis por meio da dimensão 1 (em negrito), sendo que o nível "coletado indiretamente" também pode ser interpretado pela dimensão 2 (em negrito). Já a Tabela 6 , tem todos os seus níveis mais bem representados pela dimensão 1 (em negrito). A Figura 3 apresenta o mapa de correspondência entre os meios de destino do lixo dos domicílios e a condição de pobreza das famílias beneficiárias.

Tabela 5 - Contribuições relativas das dimensões 1 e 2 sobre os perfis de linha (destino do lixo)

\begin{tabular}{l|ll} 
Destino do lixo & Dim 1 & Dim 2 \\
\hline Coletado diretamente & $\mathbf{0 , 9 5 7}$ & 0,042 \\
Coletado indiretamente & $\mathbf{0 , 5 8 7}$ & $\mathbf{0 , 4 1 3}$ \\
Jogado terreno baldio ou rio & $\mathbf{0 , 9 1 9}$ & 0,080 \\
Queimado/enterrado & $\mathbf{0 , 9 9 2}$ & 0,007
\end{tabular}

Fonte: Elaboração própria com base nos dados do Cadastro Único para Programas Sociais do Governo Federal (CadÚnico) (BRASIL, 2014)

Tabela 6 - Contribuições relativas das dimensões 1 e 2 sobre os perfis de coluna (estratificação da renda)

\begin{tabular}{l|ll}
\hline Estratificação da renda & Dim 1 & Dim 2 \\
\hline Pobreza & $\mathbf{0 , 9 6 8}$ & 0,031 \\
Extrema pobreza & $\mathbf{0 , 9 9 9}$ & 0,001 \\
Vulnerável & $\mathbf{0 , 7 2 7}$ & 0,271 \\
\hline
\end{tabular}

Fonte: Elaboração própria com base nos dados do Cadastro Único para Programas Sociais do Governo Federal (CadÚnico) (BRASIL, 2014) 


\section{REA - Revista de estudos ambientais (Online) v.20, n. 1, p.58-69, jan./jun. 2018}

A análise de correspondência apresentada na Figura 3 mostra que famílias beneficiárias em situação de extrema pobreza estão associadas a domicílios onde 0 descarte do lixo ocorre de maneira inapropriada (queimado/enterrado e jogado em terreno baldio). Famílias em situação de pobreza apresentaram associação com domicílios cuja forma de coleta do lixo é indireta, ou seja, os moradores transportam o lixo doméstico até pontos fixos - geralmente uma rua principal, na qual seja possível o tráfego de veículos maiores - para o seu descarte, onde posteriormente é recolhido por caminhões do serviço municipal de coleta. Já no caso das famílias em situação de vulnerabilidade, verificou-se associação das mesmas com moradias com cobertura total pelo serviço municipal de coleta de lixo (recolhido diretamente).

Figura 3 - Análise de correspondência entre a forma de destino do lixo e a condição de pobreza das famílias beneficiárias pelo Programa Bolsa Família no município

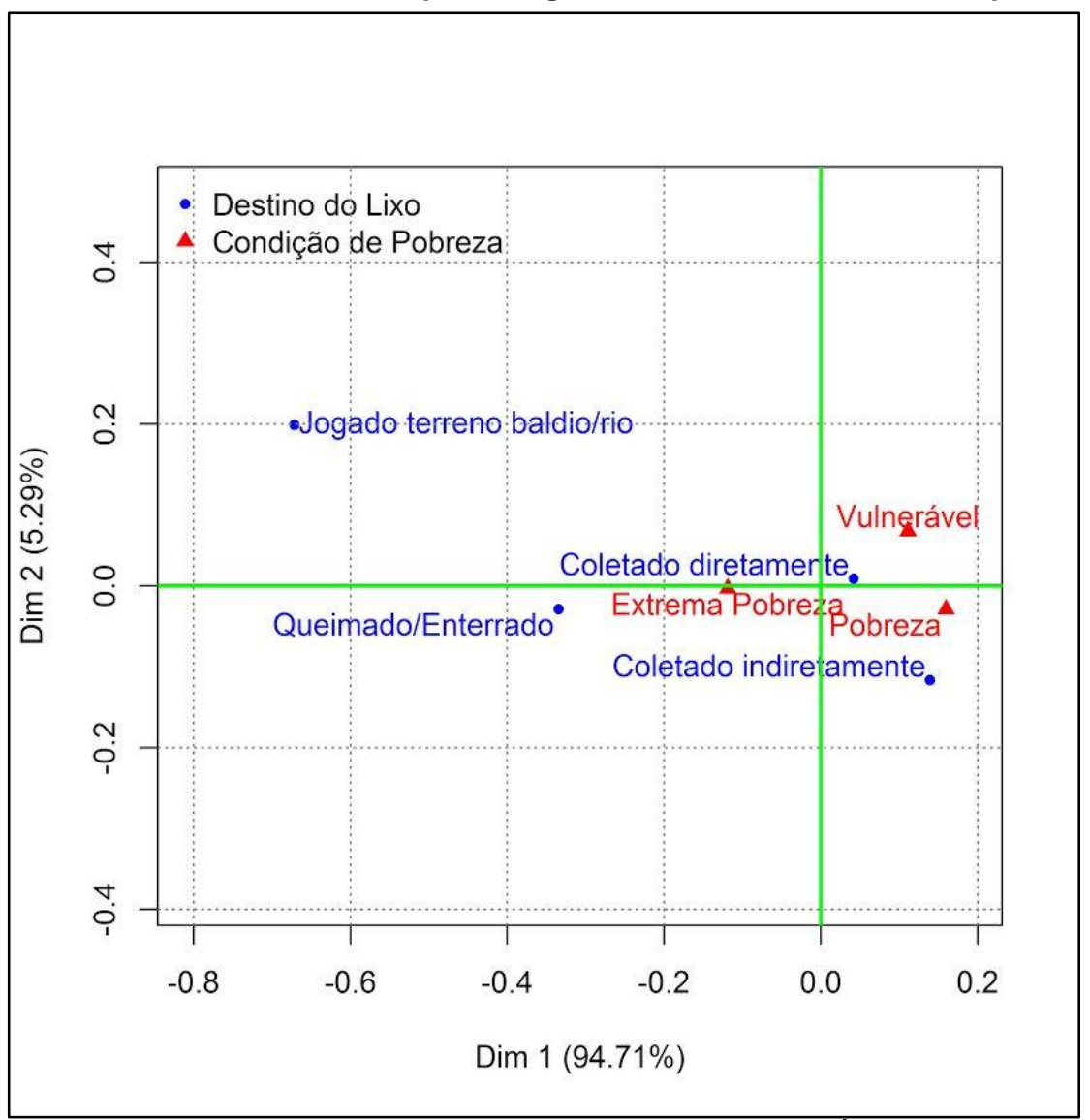

Fonte: Elaboração própria com base nos dados do Cadastro Único para Programas Sociais do Governo Federal (CadÚnico) (BRASIL, 2014)

Para a interpretação da associação entre os perfis linha (tipo de parede: alvenaria/tijolo com revestimento; alvenaria/tijolo sem revestimento; madeira/taipa) e coluna (estratificação da renda: pobreza; extrema pobreza e vulnerável), utilizam-se as Tabelas 7 e 8 , respectivamente. Ambas, possuem melhor representação de seus níveis por meio da dimensão 1 (em negrito).

Tabela 7 - Contribuições relativas das dimensões 1 e 2 sobre os perfis de linha (Tipo de parede)

\begin{tabular}{l|ll} 
Tipo de parede & Dim 1 & Dim 2 \\
\hline Alvenaria/Tijolo com Revestimento & $\mathbf{0 , 9 9 8 5}$ & 0,0015 \\
Alvenaria/Tijolo sem Revestimento & $\mathbf{0 , 9 9 5 2}$ & 0,0048 \\
Madeira/Taipa & $\mathbf{0 , 9 5 8 4}$ & 0,0416
\end{tabular}

Fonte: Elaboração própria com base nos dados do Cadastro Único para Programas Sociais do Governo Federal (CadÚnico) (BRASIL, 2014) 


\section{REA - Revista de estudos ambientais (Online) v.20, n. 1, p.58-69, jan./jun. 2018}

Tabela 8 - Contribuições relativas das dimensões 1 e 2 sobre os perfis de coluna (estratificação da renda)

\begin{tabular}{l|ll}
\hline Estratificação da renda & Dim 1 & Dim 2 \\
\hline Pobreza & $\mathbf{0 , 9 9 1 4}$ & 0,0086 \\
Extrema pobreza & $\mathbf{0 , 9 9 9 0}$ & 0,0010 \\
Vulnerável & $\mathbf{0 , 9 4 0 5}$ & 0,0595 \\
\hline
\end{tabular}

Fonte: Elaboração própria com base nos dados do Cadastro Único para Programas Sociais do Governo Federal (CadÚnico) (BRASIL, 2014)

O mapa de correspondência (Figura 4) mostra a associação entre famílias beneficiárias em situação de pobreza extrema e domicílios cujas paredes são de alvenaria/tijolo sem revestimento, seguida de associação com domicílios com paredes construídas de madeira/taipa. As famílias em situação de pobreza também se associaram com a variável alvenaria/tijolo com revestimento no que diz respeito ao material empregado nas paredes de suas residências, bem como àquelas classificadas como vulneráveis.

Figura 4 - Análise de correspondência entre o tipo de parede dos domicílios e a condição de pobreza das famílias beneficiárias pelo Programa Bolsa Família no município

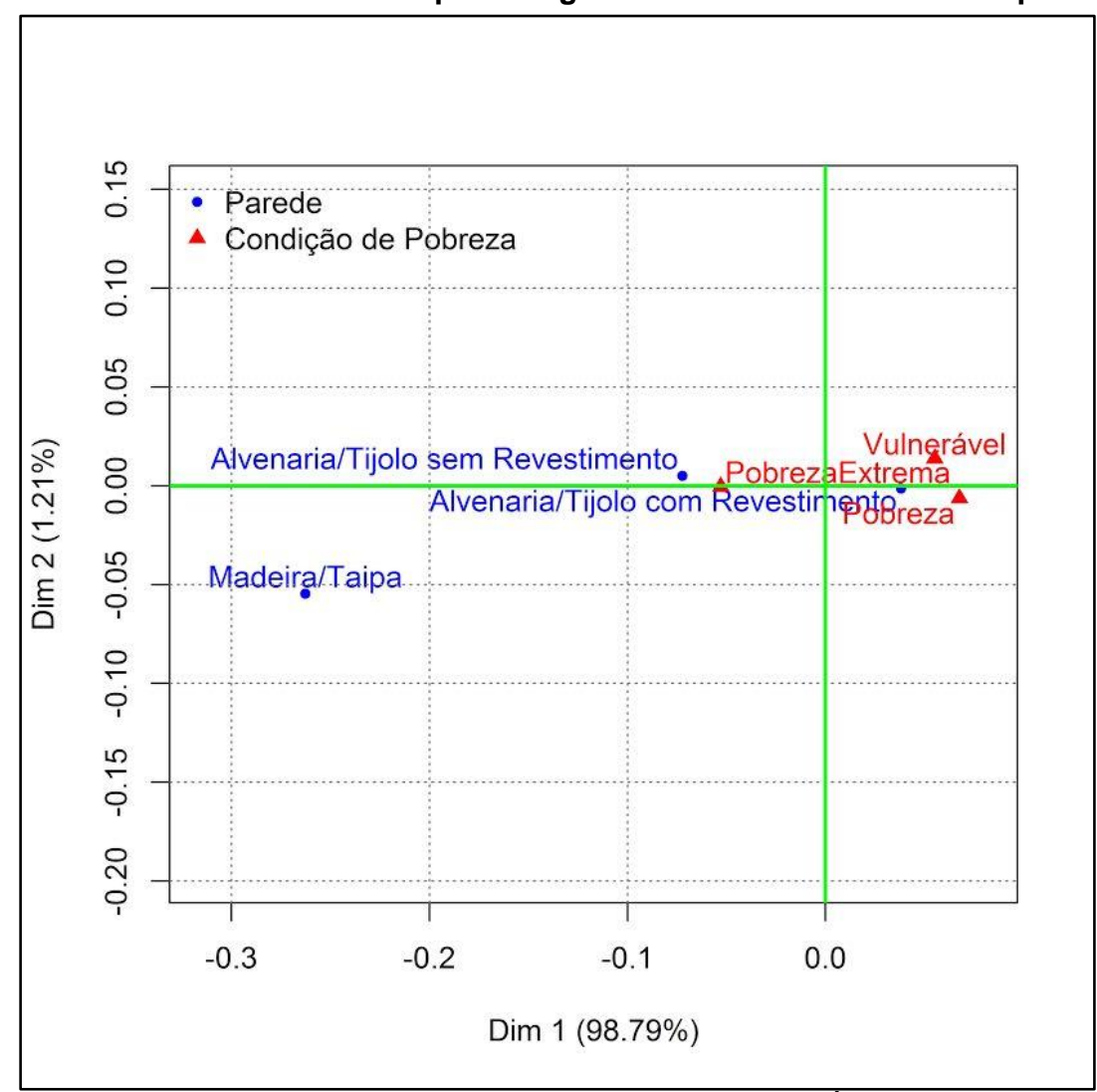

Fonte: Elaboração própria com base nos dados do Cadastro Único para Programas Sociais do Governo Federal (CadÚnico) (BRASIL, 2014)

As Tabelas 9 e 10 correspondem aos perfis linha (tipo de piso: cerâmica/lajota/pedra; cimento; madeira; terra/carpete/outros) e coluna (estratificação da renda: pobreza; extrema pobreza e vulnerável), respectivamente. Na Tabela 9, os níveis são mais bem representados pela dimensão 1 (em negrito), exceto para o nível "Terra/Carpete/Outros" iii, com maior contribuição quando interpretado na dimensão 2 (em negrito), enquanto a Tabela 10 tem todos os seus níveis melhor representados pela dimensão 1 (em negrito). A Figura 5 apresenta 0 mapa de correspondência entre o tipo de piso dos domicílios e a condição de pobreza das famílias beneficiárias. 
REA - Revista de estudos ambientais (Online) v.20, n. 1, p.58-69, jan./jun. 2018

Tabela 9 - Contribuições relativas das dimensões 1 e 2 sobre os perfis de linha (tipo de piso)

\begin{tabular}{l|ll}
\hline Tipo de piso & Dim $\mathbf{1}$ & Dim 2 \\
\hline Cerâmica/Lajota/Pedra & $\mathbf{0 , 9 8 0 0}$ & 0,0200 \\
Cimento & $\mathbf{0 , 9 9 9 9}$ & 0,0001 \\
Madeira & $\mathbf{0 , 9 4 0 9}$ & 0,0591 \\
Terra/Carpete/Outros & 0,3125 & $\mathbf{0 , 6 8 7 5}$
\end{tabular}

Fonte: Elaboração própria com base nos dados do Cadastro Único para Programas Sociais do Governo Federal (CadÚnico) (BRASIL, 2014)

Tabela 10 - Contribuições relativas das dimensões 1 e 2 sobre os perfis de coluna (estratificação da renda)

\begin{tabular}{l|ll}
\hline Estratificação da renda & Dim 1 & Dim 2 \\
\hline Pobreza & $\mathbf{0 , 9 8 2 9}$ & 0,0171 \\
Extrema pobreza & $\mathbf{0 , 9 9 9 4}$ & 0,0006 \\
Vulnerável & $\mathbf{0 , 8 0 7 0}$ & 0,1930 \\
\hline
\end{tabular}

Fonte: Elaboração própria com base nos dados do Cadastro Único para Programas Sociais do Governo Federal (CadÚnico) (BRASIL, 2014)

De acordo com a Figura 5, pode-se verificar associação entre as famílias em situação de extrema pobreza e residências cujo piso é de cimento, além da associação com domicílios que possuem piso do tipo terra/carpete/outros. As famílias em situação de pobreza apresentaram associação com domicílios cujo piso é de madeira, e aquelas em vulnerabilidade com domicílios com piso de cerâmica/lajota/pedra.

Figura 5 - Análise de correspondência entre o tipo de piso dos domicílios e a condição de pobreza das famílias beneficiárias pelo Programa Bolsa Família no município

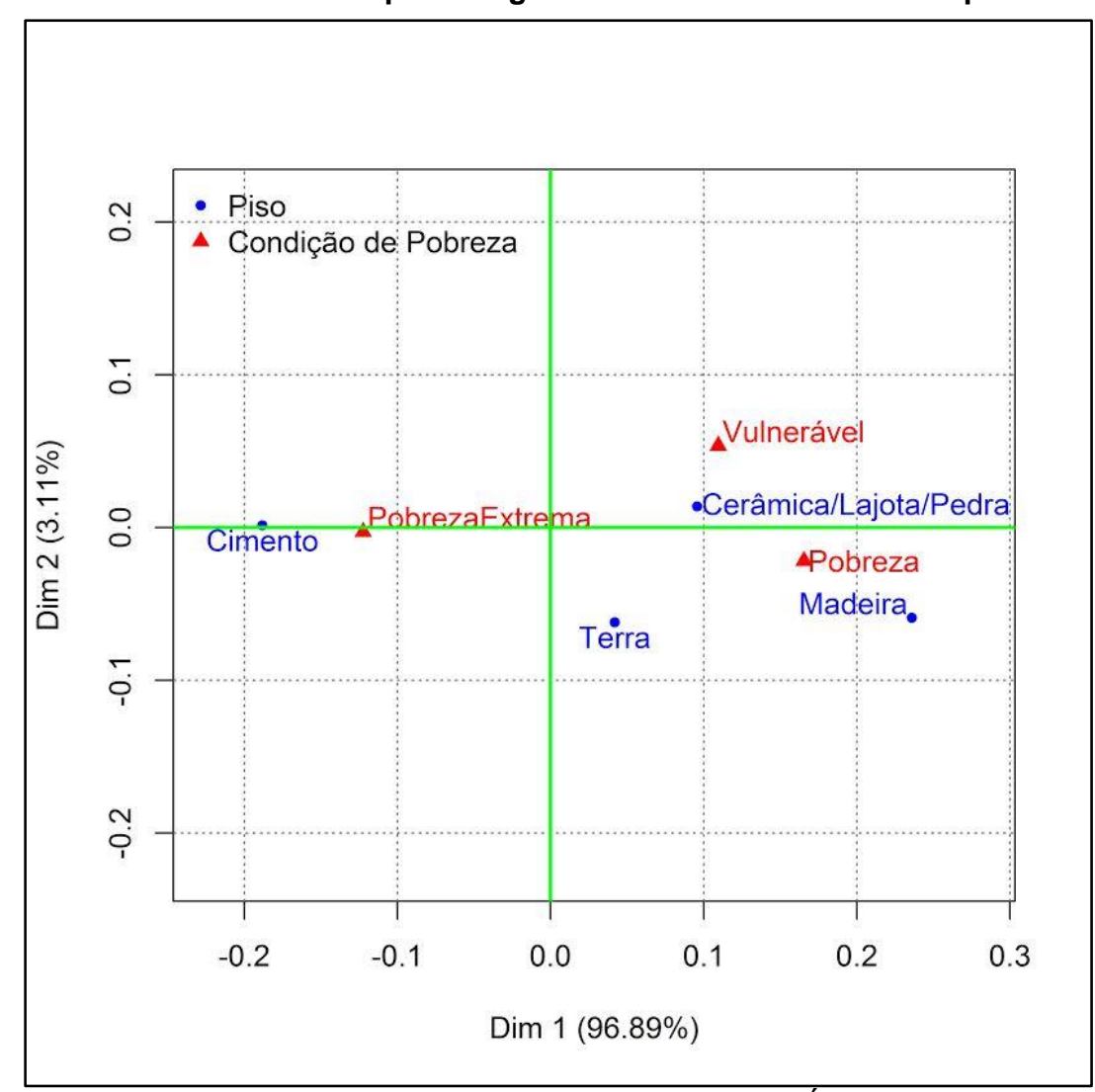

Fonte: Elaboração própria com base nos dados do Cadastro Único para Programas Sociais do Governo Federal (Cadúnico) (BRASIL, 2014) 


\section{REA - Revista de estudos ambientais (Online) v.20, n. 1, p.58-69, jan./jun. 2018}

Os achados revelaram a existência de associações entre as inadequações sanitárias, de abastecimento e condições estruturais de moradia com a situação de pobreza das famílias beneficiárias pelo PBF no município estudado. Essas iniquidades mostraram-se mais graves conforme a severidade da pobreza. Um estudo transversal conduzido por Magalhães et al. (2013), sobre as condições de vida de 76 famílias beneficiárias pelo PBF, na cidade de Paula Cândido, Minas Gerais, apontou falhas no serviço de saneamento básico e habitações em condições insalubres, o que corrobora com os resultados encontrados neste estudo.

O serviço de saneamento básico engloba a prestação do abastecimento de água, esgotamento sanitário e coleta de lixo. Dados referentes ao Censo Demográfico de 2010, do Instituto Brasileiro de Geografia e Estatística (IBGE), para Ouro Preto, demonstram que $4,9 \%$ dos domicílios possuem saneamento inadequado, 23,1\% semi-adequado e $72 \%$ adequado (IBGE, 2010). Segundo Veiga (2011), 56\% da população brasileira não têm acesso a esse serviço primordial, e a sua universalização, considerando os investimentos no setor, tornar-se-á possível apenas no ano de 2060.

Em relação ao abastecimento de água, pode-se observar a existência de famílias que ainda não usufruem do abastecimento via água encanada, ou seja, utilizam aquela proveniente de outras fontes, como nascentes e poços. A questão da origem da água deve ser pensada com maior atenção, uma vez que as condições de canalização, mesmo via rede pública de abastecimento, não garantem totalmente a sua qualidade, sobretudo em localidades sem estação de tratamento de água e esgoto. Fonseca (2008), ao pesquisar sobre a distribuição espacial das parasitoses e condições de saneamento em Ouro Preto, encontrou relação direta da má qualidade da água com o agravamento dos quadros de adoecimento. Em outro estudo, Visser et al. (2011) encontraram forte associação entre parasitoses intestinais e a procedência da água utilizada nos lares do município de Manaus. De acordo com Juliano, Malheiros e Marques (2016), a ausência de água potável indica um dos primeiros sinais de vulnerabilidade de uma população.

Outro aspecto a se considerar é o fato das Companhias de Abastecimento e Saneamento obedecerem às normas de uso e ocupação do solo para a provisão dos serviços água e esgotamento sanitário às populações. Tendo em vista o processo de crescimento desordenado das cidades e a periferização da população mais pobre, a precariedade de tais serviços encontra sustento nos fenômenos da segregação socioespacial e exclusão social (MARICATO, 2013; ALVES; CAVENAGHI, 2016; JULIANO; MALHEIROS; MARQUES, 2016). Pires (2008) e Juliano, Malheiros e Marques (2016) observaram que regiões de baixa renda são mais vulneráveis do ponto de vista socioambiental, e consequentemente sofrem mais intensamente das precariedades relativas ao setor de saneamento.

Sobre o destino do esgoto das residências onde vivem as famílias beneficiárias, é possível observar práticas não ideais e/ou inadequadas, como o uso de fossas e despejo de dejetos diretamente em rios ou valas a céu aberto. $O$ fato de os domicílios conterem banheiro não implica necessariamente em instalações e escoamento sanitário adequados, uma vez que cabines "out door" com fossas, podem ser, muitas vezes, entendidas como "banheiros". Dados do Instituto Brasileiro de Análises Sociais e Econômicas (IBASE), 2008 , revelaram que apenas $42,6 \%$ dos beneficiários do PBF possuíam acesso à rede de esgoto.

Quanto ao descarte do lixo, condutas inapropriadas como a sua queima, enterramento e/ou despejo em terrenos baldios foram constatadas, sugerindo deficiência na execução do serviço municipal de coleta. O lixo acumulado ou mal acondicionado, além do mau cheiro produzido, contribui para a proliferação de insetos e roedores condutores de doenças, e para a contaminação dos solos e recursos hídricos, causando danos à natureza e à saúde humana (SILVA et al., 2015; VIANNA, 2015).

Tendo em vista o material empregado na construção das casas, predominaram as paredes de alvenaria e tijolo com revestimento, seguidas de alvenaria e tijolo sem revestimento, e pisos de cerâmica, lajota ou pedra, logo depois cimento e terra, indicando, mesmo que em menor escala, a existência de residências com falta de adequação estrutural e moradias insalubres. Tais achados assemelham-se aos do estudo conduzido por Magalhães et al. (2013), ao obter resultados muito próximos no que diz 
REA - Revista de estudos ambientais (Online) v.20, n. 1, p.58-69, jan./jun. 2018

respeito às condições de moradia das famílias beneficiárias pelo PBF.

As análises de correspondência exibiram, igualmente, para as circunstâncias de habitação, a relação entre a condição de pobreza e a precariedade dos domicílios. Residências consideradas de má qualidade possuem estreito elo com o desenvolvimento de doenças respiratórias. Além disso, paredes sem revestimento servem de abrigo para vetores causadores de doenças (ANTUNES et al., 2013).

De acordo com Alves e Cavenaghi (2016), as condições de moradia de uma população são importantes indicadores das desigualdades sociais, e excludentes e desiguais no Brasil e na América Latina. Para os autores, um domicílio é considerado habitável quando preenche requisitos mínimos de construção e conservação, o que implica em geração de custos para as famílias. Dessa forma, levando em conta os resultados obtidos neste estudo, pode-se dizer que, assim como a gravidade da situação de pobreza, o aumento da renda e a melhoria da qualidade de vida das populações estão diretamente correlacionados às melhorias, também, das condições de moradia.

Alves (2013), ao analisar a vulnerabilidade socioambiental na escala intraurbana (setores censitários) em Cubatão, SP, descobriu a existência conjunta e a sobreposição espacial das condições de pobreza e vulnerabilidade socioambiental, fortalecendo a ideia de que as cartografias sociais tendem a sobrepor as ambientais. Nesse sentido, as condições estruturais e de saneamento dos domicílios onde se encontram as famílias beneficiárias pelo PBF podem ser consideradas como poderosos indicadores de qualidade de vida, pois questões relacionadas a possíveis fragilidades nesse contexto são sinais nítidos de subdesenvolvimento e estão intimamente vinculadas à pobreza e miserabilidade (MAGALHÃES et al., 2013; MAZARI et al., 2013; REZENDE, 2014).

\section{Conclusões}

Este estudo pode ser considerado como um aporte às políticas públicas sociais e de saúde, e ferramenta de avaliação e diagnóstico da qualidade de vida e bem-estar das populações, de modo a nortear estratégias a serem (re) definidas pelos governantes. Para tanto, há de se assegurar a confiabilidade e excelência no preenchimento dos dados, muito criticada $e$ considerada uma limitação comum aos estudos que utilizam dados secundários $e$ agregados. $O$ mau preenchimento das informações inviabiliza 0 uso de variáveis complementares, fato que deve chamar a atenção à necessidade de treinamento de recursos humanos designados a lidar com informações que alimentam as bases de dados governamentais.

Ao diagnosticar que as famílias pertencentes aos estratos mais baixos de renda possuem maior dificuldade de acesso ao saneamento básico adequado e piores condições de moradia, busca-se compreender a pobreza como um conjunto de múltiplas privações, reafirmando o fato de que viver em uma situação sanitária/habitacional ruim fortalece o cenário das desigualdades e de violação dos direitos humanos. Nessa linha de raciocínio, os resultados sugerem ao poder público adotar medidas dentro do setor de saneamento que complementem as políticas de transferências de renda, no caso brasileiro: o PBF, pois como discutido anteriormente, para vencer as desigualdades de renda é necessário, do mesmo modo, combater as disparidades socioambientais.

Por fim, crendo serem injustificáveis todas as formas de injustiça social, é importante salientar que a execução de tais ações exige atores comprometidos com 0 bem-estar, desenvolvimento humano e erradicação da pobreza, objetivando combater as estruturas, de toda ordem, alicerces das iniquidades sociais, e buscando minimizar, o quanto possível, os efeitos nocivos de ações e políticas públicas verticalizadas e descontínuas.

\section{Bolsa Família Program - An analysis from the perspective of the socio-environmental conditions in which the beneficiary families live, in a municipality of Serra do Espinhaço, MG, Brazil}

Abstract: The impact of the Bolsa Familia (family grant) program (PBF) on the lives of millions of Brazilian families is undeniable, however, there are countless structures that support social inequality in Brazil, including the socio-environmental conditions in which people live. Considering the importance of integrating public policies 


\section{REA - Revista de estudos ambientais (Online) v.20, n. 1, p.58-69, jan./jun. 2018}

to the PBF, this study proposed to investigate, by using the Correspondence Analysis (AC) technique, associations between the poverty situation of the PBF beneficiary families, living in a municipality of Serra do Espinhaço, in the interior of the state of Minas Gerais, Brazil, with the socio-environmental conditions in which they live. The results revealed precarious conditions regarding the provision of basic sanitation services in the municipality and the structural situation of houses. In addition, the diagnosed environmental unhealthiness proved to be graver depending on the severity of poverty. Considering that the phenomenon of poverty runs through the mechanisms of income, but does not end in them, it is of the utmost importance that public policies, in this sense, are elaborated and articulated to income transfer programs - in the Brazilian case, to the PBF, so as to weaken the scenario of inequalities in the country.

Keywords: Bolsa Família Program, socio-environmental determinants, poverty, correspondence analysis.

\section{Referências}

ALVES, H. P. F. Análise da vulnerabilidade socioambiental em Cubatão-SP por meio da integração de dados sociodemográficos e ambientais em escala intraurbana. Rev. Brasileira de Estudos de População, v. 30, n. 2, p. 349-366, 2013.

Vulnerabilidade socioambiental na metrópole paulistana: uma análise espacial de problemas e riscos sociais e ambientais. Rev. Brasileira de Estudos Populacionais v.23, n.1, p.43-59, 2006.

ALVES, J. E. D; CAVENAGHI, S. Déficit habitacional, famílias conviventes e condições de moradia. Séries Demográficas, v. 3, p. 257-286, 2016.

ANTUNES, F. P; COSTA, M. C. N; PAIN, J. S; SILVA, L. M. V; CRUZ, A. A; NATIVIDADE, M; BARRETO, M. L. Desigualdades sociais na distribuição espacial das hospitalizações por doenças respiratórias. Cad. Saúde Pública, Rio de Janeiro, v. 29, n. 7, p. 1346-1356, 2013.

BRASIL. MINISTÉRIO DO DESENVOLVIMENTO SOCIAL E AGRÁRIO. Programa Bolsa Família. Brasília, DF, 2014. Disponível em: <http://mds.gov.br/assuntos/bolsa-familia>. Acesso em: ago. 2016.

FERREIRA, A. B. H. Dicionário da Língua Portuguesa. 5. ed, São Paulo: Positivo, 2010, $2222 \mathrm{p}$.

FONSECA, E. S. Estudo da distribuição espacial de parasitoses e condições de saneamento básico para o município de Ouro Preto/ MG, com o apoio do Geoprocessamento. Belo Horizonte, 2008. 177 p. Dissertação (Programa de Pós-Graduação em Geografia) - Instituto de Geociências. Universidade Federal de Minas Gerais. Minas Gerais, 2008. Disponível em: $<w w w$.bibliotecadigital.ufmg.br>. Acesso em: ago. 2016.

FOUNDATION FOR STATISCAL COMPUTING VIENNA. $\mathbf{R}$ Core Team. R: A language and environment for statiscal computing. R Foundation for Statiscal Computing Vienna, Áustria, 2014.

INFANTOSI, A. F. C; COSTA, J. C. G. D; ALMEIDA, R. M. V. R. Análise de Correspondência: bases teóricas na interpretação de dados categóricos em Ciências da Saúde. Cad. de Saúde Pública, v. 30, n. 3,p. 473-486, 2014.

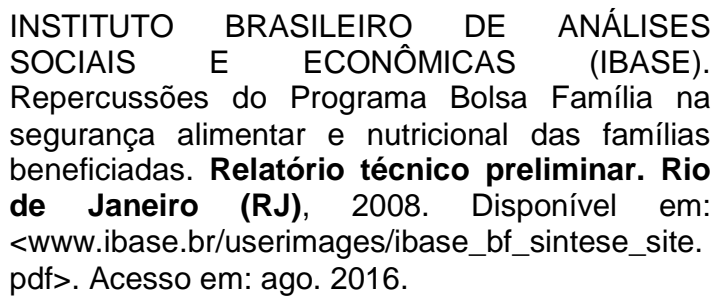

INSTITUTO BRASILEIRO DE GEOGRAFIA E ESTATÍ́STICA (IBGE). Censo 2010. Ouro Preto, Minas Gerais. Informações completas. Ouro Preto, $2010 . \quad$ Disponível em: $<$ https://cidades.ibge.gov.br/painel/populacao.php ?codmun=314610 > . Acesso em: ago. 2016.

JULIANO, E. F. G. A; MALHEIROS, T. F; MARQUES, R. C. Lideranças comunitárias e o cuidado com a saúde, o meio ambiente e o saneamento nas áreas de vulnerabilidade social. Rev. Ciência \& Saúde Coletiva, v. 21, n. 3, p. 789796, 2016.

MAGALHÃES, K. A, COTTA, R. M. M; MARTINS, T. C. P; GOMES, A. P; BATISTA, R. S. A Habitação como Determinante Social da Saúde: percepções e condições de vida de famílias cadastradas no Programa Bolsa Família. Rev. Saúde e Sociedade, v. 22, n. 1, p. 57-62, 2013.

MARICATO, E. Metrópole, legislação e desigualdade. Rev. Estudos Avançados, v. 17, n. 48, p. 151-167, 2013.

MARQUES, E. C. Redes Sociais, segregação e pobreza. São Paulo (SP): UNESP, 2010. 216 p.

MAZARI, C. K; BACKES, D. S; BACKES, M. S; MARCHIORI, M. T; SOUZA, M. T; CARPES, A. D. Realidade sociopolítica, ambiental e de saúde de famílias pertencentes a uma comunidade vulnerável. Rev. Ciência \& Saúde Coletiva, v. 8, n. 1 , p. $77-84,2013$ 


\section{REA - Revista de estudos ambientais (Online) v.20, n. 1, p.58-69, jan./jun. 2018}

NASCIMENTO, A; ALMEIDA, R. M. V. R; CASTILHO, S. R; INFANTOSI, A. F. C. Análise de correspondência múltipla na avaliação de serviços de farmácia hospitalar no Brasil. Cad. de Saúde Pública, v. 29, n. 6, p. 1161-1172, 2013.

PIRES, A. Bolsa Família e políticas públicas universalizantes: o caso de um município paulista. Cad. de Pesquisa, v. 38, n. 14, p. 341-366, 2008.

REZENDE, M. J. Os Relatórios do Desenvolvimento Humano e o papel do poder público local no combate à privação e à impotência. Rev. Latinoamericana Polis, v. 3, n. 39, p. 1-20, 2014.

SILVA, R. S; MELO, D. G; MORAES, F. J. S; ANTÔNIO, T; COELHO, T. P. M; SILVA, G. S. Impactos ambientais referentes a não coleta de lixo e reciclagem. Rev. Ciências Exatas e Tecnológicas, v. 2, n. 3, p.63-76, 2015.

SOBRAL, A; FREITAS, C. M. Modelo de Organizações de Indicadores para Operacionalização dos Determinantes Socioambientais de Saúde. Rev. Saúde e Sociedade, v. 19, n. 1, p. 35-47, 2010.

VEIGA, J. E. Saneamento básico. Núcleo de Economia Socioambiental (NESA). Universidade de São Paulo. São Paulo (SP), 2011.
VÉRAS, M. P. B. Cidade, vulnerabilidade e território. Rev. Ponto e Vírgula: Revista de Ciências Sociais da Pontifícia Universidade Católica de São Paulo, n. 7, p. 32-40, 2010.

VIANNA, A. M. Poluição ambiental, um problema de urbanização e crescimento desordenado das cidades. Rev. Sustinere, v. 3, n.1, p. 22-42, 2015.

VISSER, S; GIATTI, L. L; CARVALHO, R. A; GUERREIRO, J. C. H. Estudo da associação entre fatores socioambientais e prevalência de parasitose intestinal em áreas periféricas da cidade de Manaus. Rev. Ciência \& Saúde Coletiva, v. 16, n. 8, p. 3481-3492, 2011.

\section{Agradecimentos}

Agradecimentos especiais à Secretaria Municipal de Desenvolvimento Social, Habitação e Cidadania, e à Coordenação do Programa Bolsa Família de Ouro Preto, MG, pela liberação dos dados do Cadastro Único para Programas Sociais do Governo Federal (CadÚnico) para a realização do estudo.

\footnotetext{
' Linhas da pobreza extrema e pobreza do PBF, segundo estratos definidos a partir da renda domiciliar per capita: extrema pobreza (famílias com renda inferior a $\mathrm{R} \$ 85,00$ - oitenta e cinco reais), pobreza (famílias com renda entre $R \$ 85,01$ e $R \$ 170,00$ - oitenta e cinco reais e um centavo e cento e setenta reais, respectivamente). A linha de vulnerabilidade corresponde a quatro vezes o valor da linha da pobreza.

ii O processamento de todos os dados foi efetuado pelo pacote estatístico $\mathrm{R}$ (Language and Environment for Statistical Computing) versão 3.12 (2014). Este estudo foi submetido e aprovado pelo Comitê de Ética em Pesquisa (CEP) da Universidade Federal de Ouro Preto (UFOP), com Certificado de Apresentação para Apreciação Ética (CAAE) de número: 42521015.9.0000.5150.

iii Entende-se por "outros", conforme informação obtida na Coordenação Municipal do Programa Bolsa Família, chão coberto por palhas, jornais ou outro material que não esteja entre as opções de preenchimento do Cadastro Único para Programas Sociais do Governo Federal (CadÚnico).
} 